\title{
州级教育智库建设导向下科研管理创新的价值、 困境与实践路径
}

\section{Value, Predicament and Practice Path of Scientific Research Management Innovation Under the Guidance of State-level Educational Think Tank Construction}

\author{
徐丽霞 \\ Lixia Xu \\ 延边教育科学研究所中国·吉林 延吉 133000 \\ Yanbian Institute of Educational Science, Yanji, Jilin, 133000, China
}

\begin{abstract}
摘 要: 论文针对州级教育智库建设导向下的科研管理创新过程中实现的价值、遇到的困境以及未来的实践途径等方面展 开了详细的探究，以州级教育智库的基本建设需求为基础，分别对州级教育智库建设导向下科研管理创新的价值、困境及 实践路径等进行分析，通过构建以智库建设为核心的科研管理理念、构建科研项目管理机制、完善科研成果奖励机制与评 价机制等方式来逐渐实现科研管理的创新工作。
\end{abstract}

\begin{abstract}
Based on the basic construction needs of state educational think tank, this paper probes into the value, predicament and practice path of scientific research management innovation under the guidance of state education think tank construction, analyzes the value, predicament and practice path of scientific research management innovation under the guidance of state education think tank construction, and gradually realizes the innovation of scientific research management by constructing scientific research management idea with think tank construction as the core, constructing scientific research project management mechanism, perfecting scientific research achievement reward mechanism and evaluation mechanism.
\end{abstract}

关键词：州级教育智库；科研管理创新；价值；困境；实践路径

Keywords : state-level educational think tank; scientific research management innovation; value; predicament; practice path

DOI : $10.36012 /$ sde.v2i11.2333

\section{1 引言}

近年来, 随着中国经济的快速发展，国家和社会逐渐 关注和重视发展带有中国特色的教育智库建设, 同时这一举 措也是中国科研教育贯彻落实教育大会精神的一种体现。

\section{2 州级教育智库建设导向下科研管理创新的} 价值与意义

自从中国共产党第十九次全国代表大会顺利召开后 , 具 有中国特色的教育智库建设逐渐成为当前中国治理能力发展 的重要要求。而州级教育智库的建设对于地域的教育发展、 教育决策以及教育水平的提升有着极为重要的促进作用 ${ }^{[1]}$ 。
3 目前州级教育智库建设导向下科研管理创 新面临的困境

由于在州级教育智库建设导向下的科研管理不仅需要对 自己辖区内的教育科研活动进行负责，同时还要进行一定的 科学研究工作。但是就目前教育智库建设期间科研管理工作 的创新逐渐进入到一个困境当中，主要体现在以下几个方面：

\section{1 州级教育智库管理办法的作用得不到充分的发挥}

虽然说目前的州教育研究所已经出台并执行了延边新 型教育科研智库的管理办法，同时也基于管理办法组建了一 支专业的新型教育科研专家库，但是在实际应用的过程中，

【作者简介】徐丽霞 (1972 ), 女 (满族), 吉林汪清人, 中教一级, 从事中小学教育研究。 
其所具备的价值和作用根本没有得到充分的发挥 ${ }^{[2]}$ 。另外， 在最新构建的新型教育科研专家库中严重缺乏科研成果和能 力强、素质高的科研专家。长期处于这样的发展环境下, 不 仅造成科研指导缺失, 还存在严重设为科研管理缺失现象。

3.2 科研项目的管理方式与州级教育智库的运行方 式不配套

就目前的科研管理形式而言，体现出了严重的“重视 管理，轻视指导”的现象，而州级教育科研专家库的专家、 多位教育一线的优秀教师和教研方面的专家，就人员方面仍 然选择以教研指导为核心，导致在建设州级教育智库时缺乏 专业化的科研管理人员，以至于无论是制定管理制度还是立 项或结项教育课题等都存在一定的局限 ${ }^{[3]}$ 。因对研究重难点 的把握不够准确，导致州级教育智库的运行模式与目前的科 研管理模式并不相符，这也在一定程度上限制了科研管理工 作的有序进行。

3.3 科研成果的转化与教育智库的建设质量之间存 在差异

目前人们十分重视科研成果的学术标准性, 从而在很 大程度上忽视了咨询决策的重要程度, 并且也尚末将其纳入 科研成果的考核内容当中。现阶段, 国家在科研成果的奖励 政策上相对而言更加重视对学术著作或者学术性论文的奖 励，但是奖励的同时也缺乏量化的考核方式，导致无法精准 地对科研成果进行考核。而站在成果转化的角度上, 科研成 果也无法顺利地转变为服务决策, 久而久之导致目前的教育 实践出现严重的力度不足现象。

\section{4 州级教育智库建设导向下科研管理创新的 实践路径}

\section{1 构建以智库建设为核心的科研管理理念}

为了能够更好地在州级教育智库的建设导向下实现科研 管理的创新, 必须要构建起现代化的科研管理观念, 以此来 带领所有的州级科研人员积极地参与州级教育智库的运转, 通过智库的建设来实现更好的科研管理。站在科研管理人员 的角度上，应该在管理的过程中不断地强化自身的改革创新 意识, 对管理理念进行合理的优化, 切实地掌控好未来科研 发展的方向，起到一个良好的引导作用。因此，所有的科研 管理人员都应该基于这一层面去强化自身的协同能力，将整 个科研团队进行整合优化, 形成一个强劲的攻关合力。

\section{2 构建科研项目管理机制}

构建完善的科研项目管理机制，并对科研的发展途径进 行规划是科研创新过程中尤为重要的组成部分，其目的是有 效地改变当前的客服偪化现象、科研动态管理缺失以及静态 管理存在的弊端等。为了能够顺利地建立并实施科研项目管 理机制, 一方面,需要基于课题去制定详细的科研管理流程, 并将科研管理的重点由管理科研成果转移到课题管理上; 另 一方面，针对科研成果质量构建一个质量管理体系，以此来 促进科研管理秩序化的实现，真正提高科研管理的实效性。

\section{3 完善科研成果奖励机制与评价机制}

对科研成果进行肯定、评价和奖励可以有效地为科研 的发展提供一定的指导，还能够在很大程度上激发出科研人 员的工作积极性，并在其基础上制定科学化的奖励机制，以 此来完善当前州级教育智库建设导向之下科研成果的评价 体系，同时还要以地区性的教育发展影响力和时效性为主要 的考核评价指标，将媒体解读分析、报送批示以及政府决策 咨询所具备的分值有效地提高。以良好的奖励制度来不断地 优化科研经费的管理，建立一个合理化的专项经费管理制 度, 为教育智库的后续发展提供一定的支持与保障。

\section{5 结语}

总而言之，州级教育智库的作用就是为区域教育的发 展提供一定的促进作用，更是科研成果转化与科研管理制度 创新的一种重要发展途径。因此, 为了能够寻找到一条适合 州级教育智库建设导向下科研管理创新的实践路径, 需要构 建以智库建设为核心的科研管理理念，构建科研项目管理机 制以及完善科研成果奖励机制与评价机制，进行创新；可以 充分地利用现代化的媒介实现资源信息的共享，例如，可以 借助微博、微信等新媒体将更多的科研成果展示给大家，从 而将教育智库所具备的影响力和话语权凸显出来，促进科研 管理创新的健康有序发展。

\section{参考文献}

[1] 曲中林, 杨小秋. 地方教育智库 " 六教协同 " 建设模式一以 广东省肇庆市为例 [J]. 教育理论与实践, 2019,39(10):18-22.

[2] 张学艳, 周小虎. 从文化创新视角看高校科研人才培养 [J]. 财 会月刊 (会计版),2020(9):104-108.

[3] 王清莲, 肖光华, 钟错, 等. 江苏省社区教育智库建设路径研 究 [J]. 南京广播电视大学学报, 2018(4):5-9. 